\title{
Financial Incentives for Adopting Cloud Computing in Higher Educational Institutions
}

\author{
Ali Al-Badi ${ }^{1}$, Ali Tarhini ${ }^{1} \&$ Wafaa Al-Kaaf ${ }^{1}$ \\ ${ }^{1}$ College of Economics and Political Science, Department of Information Systems, Sultan Qaboos University, \\ Muscat, Sultanate of Oman \\ Correspondence: Ali Tarhini, College of Economics and Political Science, Department of Information Systems, \\ Sultan Qaboos University, Muscat, Sultanate of Oman. Tel: 974-5012-1922. E-mail: alitarhini@squ.edu.om
}

Received: February 9, 2017

Accepted: March 2, 2017 Online Published: March 24, 2017

doi:10.5539/ass.v13n4p162

URL: https://doi.org/10.5539/ass.v13n4p162

\begin{abstract}
Teaching today relies a great deal on IT resources which require large investments and there are many higher institutions that cannot afford such investments. Educational institutions usually search for opportunities to better manage their resources, especially after the economic crisis, which has resulted in reducing government support, especially in western countries. It is argued that 'cloud computing' is one of those opportunities for any educational institution due to its benefits in terms of cost reduction. Today, 'cloud computing' can be seen as one of the latest dynamic services in the IT world because of its flexibility. This paper investigates the financial incentives for adopting cloud computing in higher educational institutions. To achieve this objective the research employs a qualitative method to collect the data. Interviews were conducted with a number of cloud service providers, experts in the field and users/potential users of the cloud. The results reveal that cloud computing drives down up-front and on-going costs, and that the number of IT staff can be reduced if the cloud is adopted. Disaster recovery and business continuity are other cost-savings areas for an educational institute in adopting the cloud, and cloud computing provides low cost testing and a development environment solution.
\end{abstract}

Keywords: cloud computing, technology adoption, financial incentives, cost saving, higher educational institutions, Oman

\section{Introduction}

Recently higher educational institutions have been facing more demands for extra technology services, but managing these demands is not an easy task (Alenezi et al., 2015; Tarhini et al., 2016; Alalwan et al., 2016). Thus the concept of cloud computing has emerged as a promising solution for those institutions that suffer from budget limitations (Mas'adeh, 2016; Al-Mascati \& Al-Badi, 2016). Cloud computing is known as a model that provides on-demand services, infrastructure, and application software over the network (Sultan, 2010; Almajali et al., 2016). Cloud computing is a new technology which provides users with storing, sharing, accessing and controlling data online in an effective manner (Yadav et al., 2014; Maqableh et al., 2014). Cloud computing is not exclusive to the business world; it also makes a huge difference in the educational world (Al-lawati \& Al-Badi, 2016; Al-Qirim et al., 2017). Therefore, a number of higher institutions have already adopted it or are considering doing so.

Adopting cloud computing brings several benefits to the higher institutions from two dimensions (the educational and financial): Firstly, in the educational field, cloud computing enables students to acquire personal portfolios, assignments and web-based self-services. Instructors will also be able to manage the large data efficiently and have access to flexible teaching systems (Yadav et al., 2014; Sharma et al., 2016). In addition, cloud computing provides both students and instructors with data availability anytime and anywhere which will enhance the whole learning experience (Kumar \& Murthy, 2013; AlKharusi \& Al-Badi, 2016). Secondly, from the financial aspect cloud computing helps universities cut down the cost because of the option of only paying for what is used (the pay-as-you-go model) (Hignite et al., 2010; Al-Qirim et al., 2017). The cost of resources will be reduced as all kinds of hardware, software, platform and unlimited storage will be shared on the cloud (Mircea and Andreescu, 2011; Yadav et al., 2014). However, institutions are still facing some challenges and concerns regarding cloud computing adoption such as security, control, preference, and reliability (Hignite et al., 2010; Karajeh et al., 2016). 
Although most studies that have been conducted on cloud computing were focusing on education as a tool to enhance learning systems, this paper will be exploring the financial incentives for adopting cloud computing in higher institutions (Al-Badi et al., 2013). It will discuss the cost reduction possible through cloud computing adoption in terms of up-front and on-going costs.

The paper is structured as follows. Section 2 reviews the related literature about cloud computing. Section 3 highlights the research methodology. Section 4 contains the findings and discussion. Finally, there are some concluding remarks and recommendations for higher educational institutions in this regard:

\section{Literature Review}

\subsection{What Is Cloud Computing?}

The term 'cloud computing' has become very popular in the world of information technology (IT) (Ercan, 2010). The American National Institute of Standards and Technology (NIST) define cloud computing as "a model for enabling ubiquitous, convenient, on-demand network access to a shared pool of configurable computing resources (e.g., networks, servers, storage, applications, and services) that can be rapidly provisioned and released with minimal management effort or service provider interaction"(Mell and Grance, 2011). In simple words, cloud computing is a model which provides convenient, flexible, dynamic resources and services (e.g., applications, storages, communication, collaboration, and infrastructure) delivered on demand over the internet (Furht \& Escalante, 2010; Dwivedi et al., 2010; Erkoç \& Kert, 2011).

Cloud computing has many benefits associated with it, such as a reduction in implementation and maintenance costs, flexibility and scalability of infrastructures, and speed of access to the market (Singh and Hemalatha, 2012). In addition, cloud computing helps in protecting the environment because it reduces energy consumption and hence its carbon footprint (Sultan, 2010; Al-Qirim, 2011; Al-Harthy \& Al-Badi, 2014; AlZadjali et al., 2015).

\subsection{Cloud Computing Service Models}

Cloud computing offers three main service models, which are Infrastructure as a Service (IaaS), Platform as a Service (PaaS) and Software as a Service (SaaS):

- Infrastructure as a Service (IaaS) is a way to deliver resources as a service over the internet, which includes a full computer infrastructure (e.g., virtualized computers, servers, storage, network, etc.) (Sultan, 2010). Instead of purchasing these fundamental computing resources, clients can acquire raw computing power as an entirely outsourced service on demand without any capital outlay (Kovačević, 2012; Orozco et al., 2015). A study done by Srinivasan (2014) declares that $73 \%$ of the users reduced their infrastructure costs because of the availability of cloud services using IaaS (Srinivasan, 2014).

- Platform as a Service (PaaS) is a platform that provides a development environment over the internet. PaaS allows developers to build their applications quickly and easily by using providers' servers without the need to buy or maintain the software and infrastructure. Developers have no control over the cloud infrastructure (network, servers, operating systems, etc.), but they may control the developed applications, and possibly the configuration settings for the application-hosting environment (Kovačević, 2012).

- Software as a Service (SaaS): is a software distribution model that provides access to applications and data through an internet connection anytime and anywhere (Erkoç \& Kert, 2011). SaaS reduces the cost of software licensing, eliminating the need for the end-user's server hardware, network security devices and software upgrade and maintenance expenses (Shunye et al., 2014). Furthermore, there will be no need for IT investment, personal computers and internet connections to obtain the required software and services (Furht \& Escalante, 2010). The following table shows a comparison between IaaS, PaaS, and SaaS service models:

Table 1. The differences between IaaS, PaaS, and SaaS; source: (Khurana and Verma, 2013)

\begin{tabular}{|c|c|c|c|c|}
\hline $\begin{array}{c}\text { Service } \\
\text { model }\end{array}$ & Paradigm shift & Characteristic & Advantage & Disadvantage \\
\hline IaaS & $\begin{array}{c}\text { Infrastructure as } \\
\text { an asset }\end{array}$ & $\begin{array}{c}\bullet \text { Platform independent. } \\
\text { Infrastructure costs are shared. } \\
\bullet \text { Pay by usage }\end{array}$ & $\begin{array}{c}\bullet \text { Reduction of ROI risk. } \\
\text { - Avoids capital } \\
\text { expenditure on } \\
\text { hardware. }\end{array}$ & $\begin{array}{c}\bullet \text { Greater long-term cost } \\
\text { Efficiency depends on } \\
\text { cloud provider's } \\
\text { capabilities. }\end{array}$ \\
\hline PaaS & $\begin{array}{c}\text { License } \\
\text { purchasing }\end{array}$ & $\begin{array}{c}\bullet \text { Consumption by cloud } \\
\text { implementation. }\end{array}$ & $\begin{array}{c}\bullet \text { Streamlined version } \\
\text { deployment. }\end{array}$ & $\begin{array}{c}\bullet \text { New security measures } \\
\text { required. }\end{array}$ \\
\hline SaaS & $\begin{array}{c}\text { Software as an } \\
\text { asset }\end{array}$ & $\begin{array}{c}\bullet \text { SLAs. } \\
\bullet \text { Cloud components. } \\
\text { expenditure on software. } \\
\text { Reduction of ROI risk. }\end{array}$ & $\begin{array}{c}\bullet \text { Centralization of data } \\
\text { requires new security } \\
\text { measures. }\end{array}$ \\
\hline
\end{tabular}




\subsection{Cloud Computing Deployment Models}

There are four deployment models of cloud computing, which are:

- The public cloud: this is a cloud model that is available to the general public and large industrial groups (Bansal et al., 2012). The public cloud is owned and provided by organizations who sell cloud services (Agarwal, 2011). Amazon Elastic-Compute-Cloud, IBM's Blue cloud, Sun Cloud, and Google App Engine are all examples of organizations selling cloud services (Rao et al., 2013). The main benefits of public cloud are that it is easy, inexpensive and scalable (Agarwal, 2011).

- Private cloud: This is a cloud model that provides a secure and separate cloud service environment that is operated only for a specified user (Rao et al., 2013; Sinjilawi et al., 2014). This type of cloud can be managed by the user or third party (Bansal et al., 2012). Since the private cloud is dedicated to a specific user, it provides more privacy, security and control (Rao et al., 2013). Implementing the private model allows the user to respond faster to business needs, reduce costs, and increase elasticity (Agarwal, 2011).

- Community cloud: This is a cloud model that is shared by a number of organizations who share a common mission and interests (Agarwal, 2011; Qasim \& Abu-Shanab, 2014). This type of cloud model can be managed by organizations or by third party (Bansal et al., 2012). Google "Gov cloud" is an example of a community cloud (Rao et al., 2013). The community cloud is more expensive than public cloud, because the costs are spread over fewer users (organizations) (Rao et al., 2013; Obeidat et al., 2016).

- Hybrid cloud: This is a model where two or more cloud models (public, private, or community) are combined together (Rao et al., 2013). This type of cloud can be maintained by internal or external providers (Agarwal, 2011). In addition, these models are bounded by standardized technology (Bansal et al., 2012). Bounding the models allows the data and applications to flow between them in a controlled manner (Rao \& Challa, 2013).

\subsection{Cloud computing in the Sultanate of Oman}

The Sultanate of Oman is a developing country which is in the process of developing infrastructure and services. As mentioned by Said Akar, regional director of EMC for the Gulf region, Oman is moving in the right direction and the adoption of cloud computing is at an advanced level (Nair, 2012). To be specific, higher educational institutions in Oman are seriously considering the inclusion of cloud computing in their IT strategy (Alkindi et al., 2015). A number of higher educational institutions in Oman have already adopted cloud computing and others are willing to adopt it in the future (Alkindi et al., 2015).

\subsection{Cloud Computing in Higher Educational Institutions}

The continuous growth in technologies increases the pressure on the institution's budget (Sultan, 2010). In addition, due to the instability of the economy today, higher institutions are facing a number of challenging factors such as increasing costs, increasing pressure on income, and competition and performance pressure (Mircea \& Andreescu, 2011). This results in pushing higher institutions to adopt services and technologies that would minimize these challenges. Cloud computing would be the optimum choice for higher institutions, due to the considerable cost advantages associated with it. By using cloud computing, higher institutions can adopt new technologies without increasing pressure on their budget (Sultan, 2010). This is because cloud computing allows organizations to save costs and investment in newer technologies.

Today, higher institutions are required to update their software and hardware in order to attract students (Sultan, 2010). Cloud computing will allow higher institutions to do so since they provide services at an affordable cost (Idowu \& Osofisan, 2012). In addition, cloud computing overcomes the challenges of traditional forms of technology in education such as the cost of hardware and software, the maintenance costs of IT setups, and a lack of trained teachers (Rao \& Challa, 2013). When cloud computing is implemented in higher institutions it results in a reduction in the size of resources (e.g. electricity, servers, switches and cables), a reduction in hardware costs, increasing the computing power and storage etc. (Saleh \& Abdalla, 2014).

Cloud computing is widely used for education purposes (Yadav, 2014). Students and teachers use cloud computing for learning, social interaction, content creation, publishing and collaboration (Yadav, 2014). The main users of cloud computing in education are: students, the faculty, administrative staff, the examination branch, and the administration branch, as shown in Figure 1 (Yadav, 2014). Cloud computing supports teachers in a number of ways such as helping teachers to prepare their teaching portfolio, presentations etc. (Rao and Challa, 2013). Moreover, cloud computing allows higher institutions to focus on teaching and research rather than spending time on IT configuration and software (Mircea \& Andreescu, 2011). 


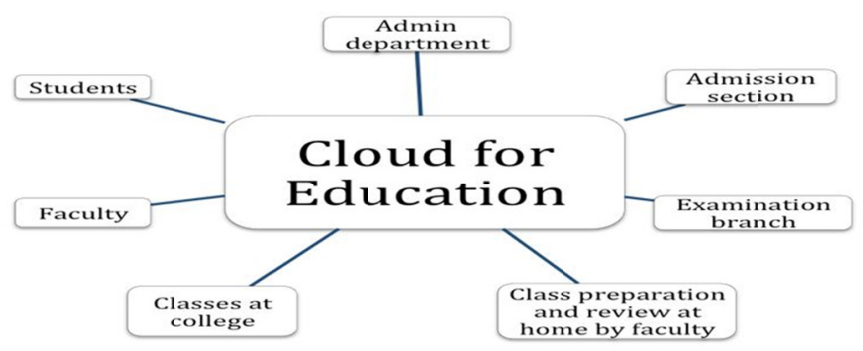

Figure 1. The users of the cloud in education; source (Yadav, 2014)

The following figure shows how higher educational institutions would utilize the cloud services:
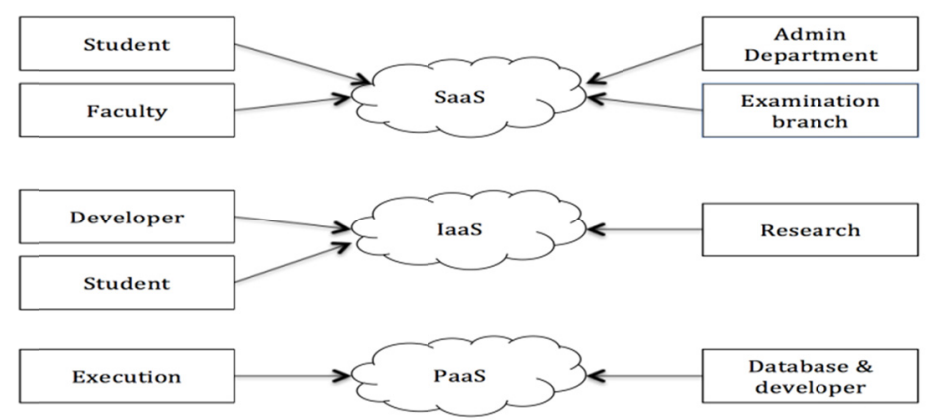

Figure 2. The usage of cloud services; source: (Yadav, 2014)

Figure 3 highlights the architecture of the cloud for education; the higher educational institutions may choose the private or educational cloud based on their needs and policies. The private cloud is appropriate for institutions who need to be able to access their own resources in the cloud (Mathew, 2012), whereas the educational cloud is appropriate for institutions that may share resources with other institutions (Mathew, 2012). In order to access the cloud services, private cloud would use the local network, whereas the educational cloud would use the public network (Mathew, 2012).

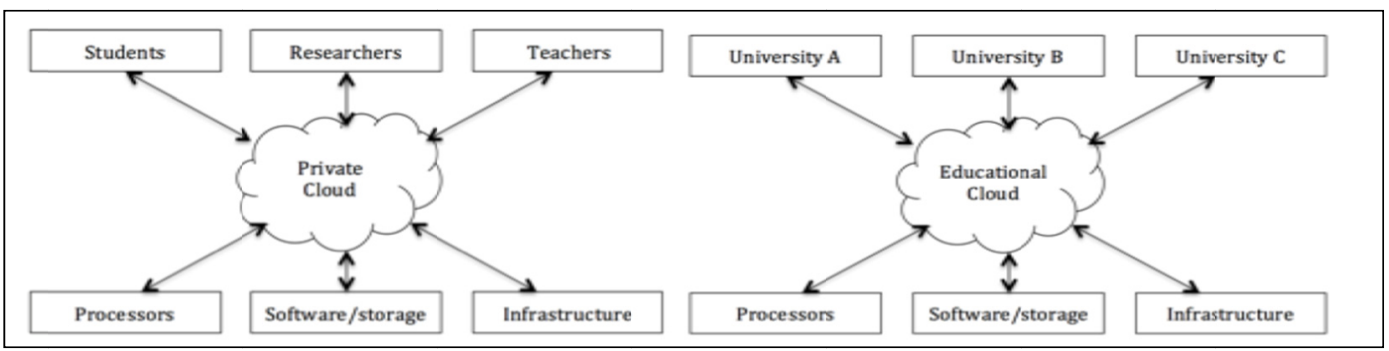

Figure 3. Cloud architecture for education; source (Mathew, 2012)

The following table shows the differences between the private cloud and educational cloud:

Table 2. The differences between the private and educational clouds; source (Mathew, 2012)

\begin{tabular}{ccc}
\hline Feature & Private cloud & Educational cloud \\
\hline Ownership \& management & Owned and managed by a single institution only. & $\begin{array}{c}\text { Owned and managed by the } \\
\text { cloud service provider. }\end{array}$ \\
Access & Only students and employees in a single institution. & On a subscription basis. \\
Customization and control & By a single institution. & None. \\
\hline
\end{tabular}

There are number of cloud service providers dedicated to education. The following table presents some of these cloud providers: 
Table 3. Cloud service providers for education; source (Lakshminarayanan et al., 2011)

\begin{tabular}{ll}
\hline $\begin{array}{l}\text { Cloud service } \\
\text { providers for } \\
\text { education }\end{array}$ & \\
\hline $\begin{array}{l}\text { 1. Microsoft } \\
\text { Live@edu }\end{array}$ & - Provides a set of hosted collaboration services. \\
& - Hosts services such as communication tools, mobile, desktop, web-based applications. \\
& - Provides data storage facilities. \\
& - Offers free registration for universities, schools, and colleges. \\
& - Offers Office Live Workspace, Windows Live SkyDrive, Windows Live Spaces, Microsoft Shared \\
& View Beta, Microsoft Outlook Live, Windows Live Messenger and Windows Live Alert. \\
& - Web-based programmes and file storage. \\
& - Accessed through the web browser. \\
& - Offers Google Apps: Gmail, Google Talk and Google Calendar. \\
& - Offers Google Docs: text files, spreadsheets and presentations. \\
& - Offers iGoogle and Google sites for web pages development. \\
& - The services are available for free, as is Premium edition (primary, secondary and higher education). \\
& - Allows institutions to keep their own domain name without changing it. \\
& - Offers web-based services in different areas: computer, software, content delivery, storage, database, \\
& deployment and management, application services, workforce. \\
& - Offers free usage credits and infrastructure for education, educators, academic researchers and \\
3. Amazon & students.
\end{tabular}

Regarding the concern that higher educational institutions have about the security of the cloud, there are a number of solutions to ensure the security and protection of their data: the masking or de-identification of the data, firewalls, encryption and key management, and authorization identity management (Mircea \& Andreescu, 2011).

Today many higher institutions use e-learning to make the process of learning easier (Viswanath et al., 2012; Tarhini et al., 2015). E-learning is based upon using software applications in the virtual learning environment (Tarhini et al., 2014). E-learning is basically "an internet-based learning process, using internet technology to design, implement, select, manage, support and extend learning, which will not replace traditional education methods but will greatly improve the efficiency of education" (Vitkar, 2012). The traditional form of e-learning requires the following: 1) cost investment on the equipment needed; 2) development of e-learning; and 3) the maintenance of e-learning (Viswanath et al., 2012). In order to avoid such requirements of e-learning, higher institutions may use e-learning cloud services. Cloud-based E-learning allows higher institutions to experience: 1) great reduction of cost; 2) improvement in performance; 3) immediate software update; and 4) improvement of document format capabilities (Viswanath et al., 2012). In addition, cloud-based e-learning can be used to overcome problems such as a lack of proper infrastructure, lack of curriculum, lack of maintenance and technical support (Karim and Goodwin, 2013; Tarhini et al., 2016). Cloud-based e-learning is divided into five layers, which are: 1) the hardware resource layer; 2) the software resource layer; 3) the resource management layer; 4) the service layer; and 5) the business application layer (Viswanath et al., 2012) as highlighted in Table 4 below.

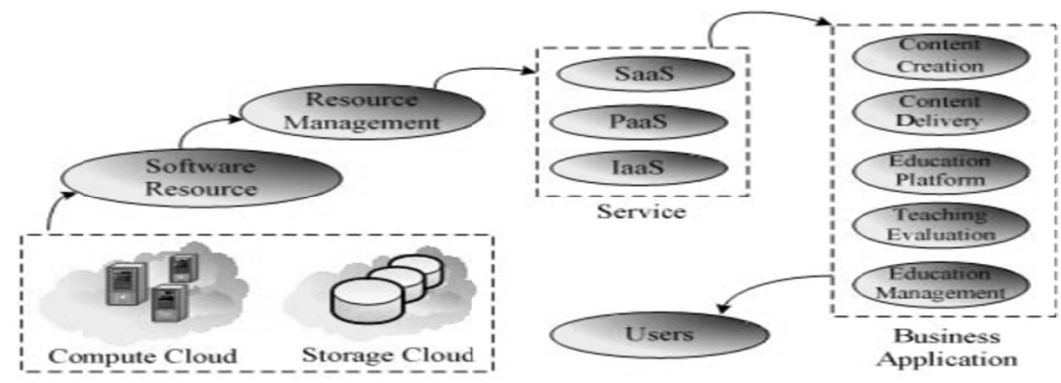

Figure 4. E-learning cloud architecture; source: (Viswanath et al., 2012)

To help higher institutions in implementing cloud computing successfully, Marinela and Ioana suggested a five step migration strategy to the cloud (Mircea \& Andreescu, 2011) as stated below and outlined in Figure 5:

1. Development of knowledge on cloud computing: attending seminars and conferences to learn more about 
cloud computing and its providers (Mircea \& Andreescu, 2011).

2. Evaluation of the current situation of the institution, (regarding IT needs, structure and usage): understanding the current institution's IT infrastructure, and identifying technologies that meet the needs of the institution (Mircea \& Andreescu, 2011).

3. Test of cloud computing solutions: undertaking developmental and environmental testing on data in the cloud, processing internal operations, and addressing components of both the public and private cloud to ensure that security and protection policies are in place (Mircea \& Andreescu, 2011).

4. Selecting cloud computing solution(s): Identifying data, applications, functions, and the main processes in the institution (Mircea \& Andreescu, 2011).

5. Implementation and management of cloud computing solution(s): The implementation can be done in iterative phases, and performed based on continuous evaluation of the cloud service benefits (Mircea \& Andreescu, 2011).

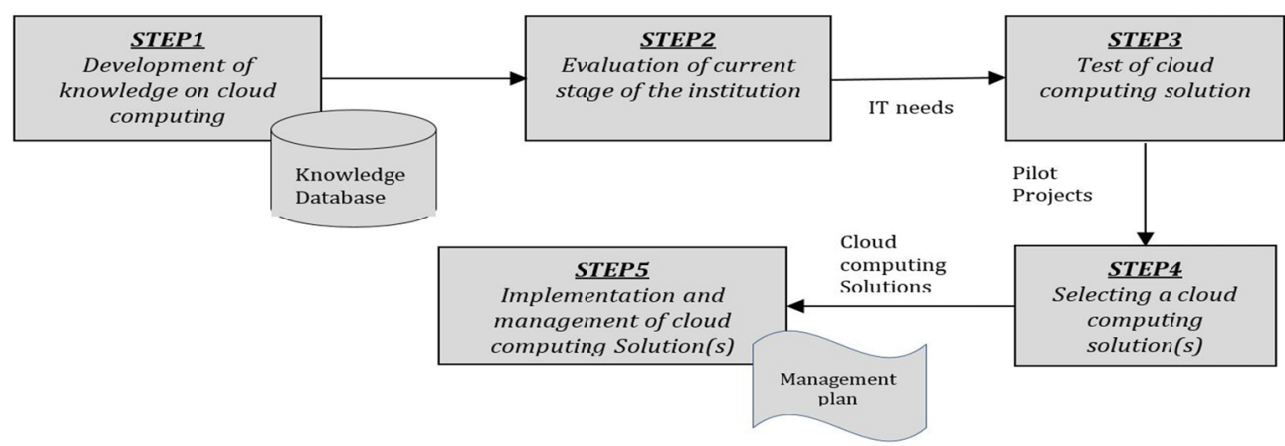

Figure 5: A five step migration strategy to the cloud; source: (Mircea and Andreescu, 2011)

\subsection{Financial Benefits of the Cloud in Higher Educational Institutions}

Nowadays many universities have recognized the potential effectiveness of using cloud computing in higher institutions. The Gartner Group found that $49 \%$ of institutions are already involved in some type of cloud computing (Carr, 2014). Cloud computing helps universities to concentrate more on the education and research activities rather than on complex IT configuration and software systems (Mircea \& Andreescu, 2011).

There are many reasons for institutions of higher education to move from traditional IT infrastructure to cloud computing. Regardless of its benefits to e-learning solutions and providing educational services directly through cloud providers, the most cited benefit of cloud computing is still the financial benefit. In fact, IDG's 2012 Cloud Computing Survey found that "even though there are higher short-term costs for implementing cloud initiatives, the majority of organizations (63\%) agree/strongly agree that there will be long-term cost savings" (Mircea \& Andreescu, 2011).

Adopting a need-based computing approach offers full up-front control of costs, which reduces capital expenditure (Erl et al., 2013). Cloud computing allows higher educational institutions to scale up or scale down resources and storage based on their current needs as institutions can start and stop resources on demand, which means that as soon as the user no longer needs the service they will stop paying for it immediately (Anand \& Kamayani, 2015; Rogers \& Cliff, 2012).

Moreover, cloud computing supports the pay-as-you-go pricing model (Chorafas, 2010). This model enables users to only pay a rental for the facilities they employ (Srinivasan, 2014). Cloud computing is likely to reduce expenditure in this area and also reduce on-going costs because institutions can lower the costs of physical space and associated overheads (Carr, 2014), equipment maintenance and upgrades, and the electricity consumption and cooling that are needed to run PCs, servers, switches, and backup drives (Sultan, 2010).

Since the infrastructure is owned by cloud service providers, there will be no need for software licensing or updating. As a result, fewer IT staff will be needed, and for those institutions that are lacking IT staff, the cloud will help them eliminate the costs of third party hardware repair bills. North Carolina State University achieved a substantial reduction in their expenses as they no longer had to pay for a software license, while at the same time reducing campus IT staff with full working schedule from fifteen to only three employees (Mircea \& Andreescu, 2011).

Furthermore, the cloud provides low cost disaster recovery (DR) solutions and reduces the impact of failures at 
the disaster site. A study conducted by Wood et al. (2010) compared the costs of running DR services using the public cloud with those of privately owned resources, and the results showed that the cost reductions increased by $85 \%$ through taking advantage of cloud resources (Wood et al., 2010). Additionally, the testing and development environment of the cloud reduces the unit cost, while increasing effectiveness. Using the cloud for testing and development allows institutions to shift from capital expenditure, CapEx, to a flexible operating expenditure model $(\mathrm{OpEx})$, since there is no longer the need to make up-front investments in infrastructure, tool licenses, and configuration and maintenance of test environments (Mylavarapu, 2011).

Apart from financial benefits, cloud computing provides many other benefits for students, teachers and institutions:

- For students: cloud computing provides them with a wide variety of resources and software tools, based on their learning interests and style (Yadav, 2014). By using cloud computing, students can access, share and publish documents, class documents, and webpages (Rao \& Challa, 2013). Moreover, students can access material anytime $(24 \times 7 \times 365)$ and from anywhere by using any device such as a PC, laptop, PDA (Kalpeyeva \& Mustafina, 2013).

- For teachers: the capabilities of cloud computing for education allows teachers to teach in new and different ways, helping the teachers to reduce their workload and project management (Rao \& Challa, 2013). In addition, teachers can access, share and publish documents and class documents (Rao \& Challa, 2013). Rather than having to carry the hard copies of documents around, teachers can access what they need through a web browser (Mathew, 2012). Teachers can also access material anytime $(24 \times 7 \times 365)$ and from anywhere by using devices such as PCs, laptops, PDA (Kalpeyeva \& Mustafina, 2013).

- For higher institutions: cloud computing allows them to use the latest technologies in order to meet the growing educational needs (Yadav, 2014). Using cloud computing in institutions reduces the carbon footprint, which helps to protect the environment (Yadav, 2014). In addition, it allows higher institutions to use and develop different software platforms without any complexity, providing institutions with high computing capacity, and allowing them to change system without any effort or loss of time (Morgado, 2011). Higher educational institutions may conduct 'virtual' classes, use 'virtual' laboratories and 'virtual' machines based on the number of students (Kalpeyeva \& Mustafina, 2013). Moreover, cloud computing allows higher institutions to outsource some of its IT functions to the cloud provider (Kalpeyeva \& Mustafina, 2013).

\subsection{Implementation of Cloud Computing in Higher Educational Institutions: Examples}

The University of Westminster (UOW) in the United Kingdom, that has more than 22,000 students, uses cloud computing in order to benefit from the services and cost advantages associated with it (Sultan, 2010). UOW uses Google cloud services (the education edition) for the email system (Google mail) (Sultan, 2010). Google mail provides services for UOW without any cost, and their email facilities include: 7.3GB capacity for each student, allows users to keep their domain names without changing it, and provides applications such as word processing, spreadsheet and presentation (Sultan, 2010). In addition, UOW estimated the cost of the same facilities, if done internally, would cost them $£ 1,000,000$, whereas Google mail costs them nothing (Sultan, 2010).

Another example is that of George Bacovia University in Romania, which has a number of problems when it comes to dealing with their independent systems, which are: the need for reliable hardware, maintenance activities on a regular basis, and difficult flow of information because the systems are not integrated (Bucşă \& Ocneanu, 2014). To overcome these problems, George Bacovia University implemented cloud services with Google apps for education (Bucşă \& Ocneanu, 2014). Google offers its services free to educational institutions (Bucşă \& Ocneanu, 2014). By implementing cloud services George Bacovia University was able to: cut costs in software licensing and maintenance of applications, cut investment in information security and maintenance, while gaining the ability to access resources anywhere and at any time, along with the ability to share information (Bucşă \& Ocneanu, 2014).

Also, Kaunas University of Technology (KUT) in Lithuania has adopted cloud computing services (Darus et al., 2015). KUT moved the following systems onto the cloud: the university e-mail system, the academic information system, the library information system, and the e-learning system (Darus et al., 2015). Implementing cloud computing allowed KUT to cut investment in resources such as hardware, software, experts etc. (Darus et al., 2015).

In general, the following is a list of potential saving areas of leasing cloud-based IT resources as opposed to the purchase of on-premise IT resources (i.e. having own data center): 
Table 4. Saving areas of leasing cloud-based IT resources

\begin{tabular}{|c|c|}
\hline Up-front costs & On-going costs \\
\hline $\begin{array}{ll}\text { - } & \text { Hardware (servers, PCs, ...etc.) } \\
\text { - } & \text { Software } \\
\text { - } & \text { IT staff (required for setup and deployment) } \\
\text { - } & \text { Disaster recovery infrastructure } \\
\text { - } & \text { Development and testing environment }\end{array}$ & $\begin{array}{ll}\text { - } & \text { Maintenance and underlying infrastructure } \\
\text { - } & \text { Licensing fees } \\
\text { - } & \text { Electricity } \\
\text { - } & \text { Software and hardware upgrading }\end{array}$ \\
\hline
\end{tabular}

*This table is only to represent the saving areas, which was investigated through the current study.

\section{Research Methodology}

A survey has been employed in this study through conducting interviews in order to explore the financial incentives for adopting cloud computing in the higher educational sector. To achieve the stated objective, three different groups participated in this research:

1) Cloud service providers: a number of interviews were conducted amongst cloud service providers to investigate the cost of building the cloud environment from different aspects, and probing the services that they offer.

2) Experts in the field: a number of interviews were conducted amongst experts in the field of cloud computing, in order to understand how cloud computing can be a better choice for higher institutions.

3) Users/potential users of the cloud: a number of interviews were conducted amongst users/potential users of the cloud in higher educational, in order to explore the financial incentives and benefits of using the cloud in educational institutions.

There were 25 interviews, 13 of them with the cloud service providers, 10 with the experts and two with users/potential users of the cloud. The survey (interview) consists of eight questions that focused mainly on the objective of this study.

\section{Findings and Discussion}

Analyzing the data collected from the interviews shows that the up-front costs (expenses that are charged at the beginning) of the cloud solution are much lower than those of the on-premise environment. Regarding the latter, experts and service providers said that there would be a requirement for huge capital expenditure (CapEX) in order to provide an integrated data center, since the educational institutes would have to buy physical servers (e.g. mail server, database servers, proxy servers, web server, etc.) and PCs. Software licenses must also be bought up-front to allow the use of mail servers and database servers (e.g. Oracle, Visual Studio, etc.). Besides, the normal data center would normally require higher energy to operate it and equipment to control the temperature of the room and to provide ventilation, fire and humidity detection, and cameras to monitor the data center may be required. If this were not enough, there is the added cost of updating the entire data center every 3-5 years. Experts looking into all this stated that the total cost would be very high.

In the case of using the cloud, service providers believe that there will also be savings in the data center architecture as institutions can eliminate the costs. The cloud provider will provide all the services discussed above and the cost will be according to usage. That is, the exact usage will be charged for hourly, monthly or annually depending on the contract.

Some of the experts highlighted that it will require time to build a new infrastructure. A typical hardware procurement can frequently take anywhere between three and four months, and this is without taking into account the effort of various members of the team from IT Director to employees in the sourcing department and so on. One expert commented that the effort of four members for four months is the equivalent of 16 members working for a month. Therefore, proper planning about building a proper cloud, whether it is private or public, can save a lot of effort, time and cost.

Regarding the users of the cloud, they have indicated that using cloud services allows the educational institutions to cut costs on hardware and software. As indicated by users, the cloud eliminates the need for owning and maintaining systems such as the student email system, student information system, learning management system etc.. This is because the cloud service providers are responsible for buying and maintaining hardware, purchasing software, and developing systems.

Cloud service providers did indicate that some on-going costs and operational fees would still depend on the type of service that the institution subscribes to. However, adopting the cloud will definitely save many operational 
hassles in maintaining the entire IT infrastructure. The adoption of cloud computing has helped to free up more than half the space in the datacenter, which has also resulted in savings in cooling (heating), and has created substantial reductions in the operational costs such as electricity, support, upgrade and maintenance costs for each of the servers. In addition, cloud providers stated that with the cloud solution the operational cost of connectivity is going to be covered by them.

However, some experts pointed out that in some countries the connectivity is quite poor and expensive. Hence, network connectivity (fiber) is probably the bottleneck to host a DR site. Nevertheless, these concerns will not last forever, as expanding the connectivity is a key demand for any country that wants to cope with the current development.

From the users' point of view, they have agreed that adopting the cloud reduces on-going costs. As an example, cloud licensing (such as MS-Office cloud licensing) is much cheaper than purchasing the physical licensing. In addition, adopting cloud educational packages such as Moodle, allows the users to obtain better service, and still at a lower cost.

Regarding the IT professionals, both providers and experts agree that there will be a straight reduction in the number of resources for operation. The institution will not require a complete operational team to operate and manage the systems because most of the infrastructure and platform-related operations will be done by the cloud team. One expert supported this by estimating the reduction in IT staff as being a possible decrease from ten employees in the normal situation to three when using cloud hosting. These findings support previous research mentioned in the literature (Mircea \& Andreescu, 2011), which indicates that with cloud the IT staff can be reduced from fifteen to three.

However, some of the participants pointed out that some IT professionals will still be required to ensure the smooth running of the cloud services. In fact, it is possible to scale down the team size, but their involvement is far greater and requires round-the-clock support to run a decent-sized cloud. It has to be noted that staff with skills to manage virtual machines (VM's), memory, VLAN creations, etc. need to be there in the IT department for effective cloud management.

In addition, providers refer to the wide range of options that the cloud offers as significant in the reduction of cost. The cloud is usually comprised of a self-service portal which enables cloud customers to create, modify or delete a VM on demand. One of the providers supports this point, indicating that the cloud offers the institutions the option of adding a new server (through a website panel) in a few minutes with a certain period of usage that they need, which is referred to as a pay-as-you-use model. Another considerably important option is to choose the exact type of virtual machine and specifications (e.g. RAM, storage, number of processers, etc.) and the price will be decided depending on that choice, and it is usually much cheaper. Payment will be made later, as time passes and resources are consumed.

Moreover, users of the cloud indicate that it provides better facilities at lower cost. By using the cloud, the users are able to utilize IT services anywhere and at any time. As an important point mentioned by the users, the cloud allows the institution to reduce the time required to help in providing better services and greater availability, and increases the total cost of ownership. In addition, the cloud allows the institutions (users) to only own the hardware that enables them to connect to the internet and use the cloud services. This reduction in IT equipment helps the institution to offload maintenance costs (such as the cost of maintaining servers, networks and security appliance hardware etc.).

Regarding Disaster Recovery (DR), service providers widely believe that adopting cloud computing for a disaster recovery is really going to benefit higher educational institutions. As users mentioned, using cloud services for DR would make it cheaper, as it will reduce the number of staff required, and therefore the cost. In addition, cloud service providers run their data centers with high redundancy and availability, making it more reliable and secure to have your environment hosted by them for business continuity. In terms of cost, it all depends on what you need, but usually it will turn out to be much cheaper in the long run, taking everything into consideration.

According to one provider's experience the whole process of setting up the DR site could be carried out in a matter of two days, since establishing DR is easy in a cloud environment, as the VM's can be copied and pasted from the production environment to the DR environment. Similarly the expert opinions match providers' views in that they believe that adopting the cloud for DR will save a great deal of capital investment (CapEX), as in the normal scenario local DR requires a prepared environment which is expensive.

What is more, establishing a testing and development environment with the cloud is much more advantageous 
for the institutions. Service providers and experts supported this point and indicated that with the cloud the ability to self-provision development and testing environments will be there. The institutions will develop applications in the cloud without having to bother about software licenses and without even having to own a platform. In addition, before launching the final services they will have the ability to test them in a reliable environment that can handle system crashes or errors rather than testing them locally, which could affect their resources. One of the experts indicated that the cloud allows collaboration with other developers, architects and designers on the development of the application. This way it will reduce the costs for institutions as there will be no need to bring the developers to the country.

\section{Conclusion}

Cloud computing is a solution for higher educational institutions that suffer from improper infrastructure and/or lack of funds. Cloud computing allows the institution to use IT resources rather than owing them. Cloud computing allows the higher educational institutions to experience cost reduction, flexibility and better services.

This study sets out to explore the financial incentives for higher educational institutions to adopt cloud computing, identifying the cost reductions it will bring. The current findings clarify the difference between cloud-based IT resources and the purchase of in-house IT resources. The most obvious findings to emerge from this study are; (1) cloud computing drives down both up-front and on-going costs; (2) the need for IT staff will be reduced when using the cloud; (3) disaster recovery and business continuity are other cost-savings areas that an educational institute can gain when adopting the cloud and (4) cloud computing provides low cost testing and development environment solutions. Overall, the cloud solution is an opportunity to reduce costs for higher educational institutions, as well as helping them to focus on the core goal.

The obvious recommendation for higher educational institutions is to start experimenting with cloud computing at least on a small scale, in order to fulfill their IT needs and requirements. In order to do this an institution can follow the five step strategy suggested by (Mircea \& Andreescu, 2011).

\section{References}

Agarwal, C. (2015). Concepts, Challenges and Opportunities of Cloud Computing for Business Analyst. AKGEC International Journal of Technology, 2(2), 28-29.

Alalwan, A. A., Rana, N. P., Algharabat, R., \& Tarhini, A. (2016, September). A Systematic Review of Extant Literature in Social Media in the Marketing Perspective. In Conference on e-Business, e-Services and e-Society (pp. 79-89). Springer International Publishing. https://doi.org/10.1007/978-3-319-45234-0_8

Al-Badi, A. H., AlHinai, Y. S., Sharma, S. K., \& Williams, S. (2013). Usage of social networking tools in research and collaboration. Journal of Emerging Trends in Economics and Management Sciences, 4(6), 515.

Alenezi, H., Tarhini, A., \& Sharma, S. K. (2015). Development of quantitative model to investigate the strategic relationship between information quality and e-government benefits. Transforming Government: People, Process and Policy, 9(3), 324-351. https://doi.org/10.1108/TG-01-2015-0004

Al-Harthy, L. Y., \& Al-Badi, A. H. (2014). To Cloudify or Not to Cloudify. World Academy of Science, Engineering and Technology. International Journal of Social, Behavioral, Educational, Economic, Business and Industrial Engineering, 8(8), 2453-2464.

Al-lawati, A., \& Al-Badi, A. H. (2016). The impact of cloud computing IT departments: A case study of Oman's financial institutions. In International Conference on Big Data and Smart City (ICBDSC), 2016 3rd MEC (pp. 1-10). IEEE. https://doi.org/10.1109/ICBDSC.2016.7460344

AlKharusi, M. H., \& Al-Badi, A. H. (2016). IT personnel perspective of the slow adoption of cloud computing in public sector: Case study in Oman. In International Conference on Big Data and Smart City (ICBDSC), 2016 3rd MEC (pp. 1-8). IEEE. https://doi.org/10.1109/ICBDSC.2016.7460364

Alkindi, Z. S., Haynes, J. and Arockiasamy, S., (2015). A Conceptual Architectural Framework of Cloud Computing for Higher Educational Institutions in the Sultanate of Oman. Journal of Emerging Trends in Computing and Information Sciences, 6(9), 482-487.

Al-Mascati, H., \& Al-Badi, A. H. (2016). Critical success factors affecting the adoption of cloud computing in oil and gas industry in Oman. In International Conference on Big Data and Smart City (ICBDSC), 2016 3rd MEC (pp. 1-7). IEEE. https://doi.org/10.1109/ICBDSC.2016.7460365

Almajali, D. A., Masa'deh, R. E., \& Tarhini, A. (2016). Antecedents of ERP systems implementation success: a study on Jordanian healthcare sector. Journal of Enterprise Information Management, 29(4), 549-565. 
https://doi.org/10.1108/JEIM-03-2015-0024

Al-Qirim, N. (2011). A Roadmap for success in the clouds. In 2011 International Conference on Innovations in Information Technology (IIT) (pp. 271-275). IEEE. https://doi.org/10.1109/INNOVATIONS.2011.5893831

Al-Qirim, N., Tarhini, A., Rouibah, K., Mohamd, S., Yammahi, A. R., \& Yammahi, M. A. (2017). Learning orientations of IT higher education students in UAE University. Education and Information Technologies, $1-14$.

Al-Qirim, N., Rouibah, K., Tarhini, A., Serhani, M. A., Yammahi, A. R., \& Yammahi, M. A. (2017). Towards a personality understanding of information technology students and their IT learning in UAE university. Education and Information Technologies, 1-12.

AlZadjali, A. M., Al-Badi, A. H., \& Ali, S. (2015, September). An Analysis of the Security Threats and Vulnerabilities of Cloud Computing in Oman. In International Conference on Intelligent Networking and Collaborative Systems (INCOS) 2015 (pp. 423-428). IEEE. https://doi.org/10.1109/incos.2015.79

Anand, H. S. \& Kamayani, (2015). Scope of Cloud Computing in Education Sector: A Review. International Journal of Recent Research Aspects, 2(2), 150-152.

Bansal, S., Singh, S. \& Kumar, A., (2012). Use of Cloud Computing in Academic Institutions. International Journal of Computer Science and Technology, 3(1), 427-429.

Bucşă, R. C. \& Ocneanu, L., (2014). Cloud Computing Technology in Educational Institutions. Economy Transdisciplinarity Cognition, 17(1), 98-102.

Carr, N. (2014). All Things Cloud: Developing an Institution-Wide Strategy. Jenzabar Inc, NY: USA.

Chorafas, D. N. (2010). Cloud computing strategies. CRC press, NY: USA. https://doi.org/10.1201/9781439834541

Darus, P., Rasli, R. B. M. \& Gaminan, N. Z., (2015). A Review on Cloud Computing Implementation in Higher Educational Institutions. International Journal of Scientific Engineering and Applied Science, 1(8), 459-465.

Dwivedi, Y. K., \& Mustafee, N. (2010). It's unwritten in the Cloud: the technology enablers for realising the promise of Cloud Computing. Journal of Enterprise Information Management, 23(6), 673-679. https://doi.org/10.1108/17410391011088583

Ercan, T., (2010). Effective use of cloud computing in educational institutions. Procedia Social and Behavioral Sciences, 2(1), 938-942. https://doi.org/10.1016/j.sbspro.2010.03.130

Erkoç, M. F. \& Kert, S. B., (2011). Cloud computing for distributed university campus: A prototype suggestion. In the proceeding of International Conference on Future of Education, Firenze (pp 10-17)

Erl, T., Puttini, R. \& Mahmood, Z. (2013). Cloud Computing: Concepts, Technology \& Architecture. Pearson Education, London, UK.

Furht, B. and Escalante, A. (2010). Handbook of cloud computing. Springer, NY: USA. https://doi.org/10.1007/978-1-4419-6524-0

Hignite, K., Katz, R. N. \& Yanosky, R. (2010). Shaping the higher education cloud. Educause and Nacubo, Columbia: USA.

Idowu, S. A. \& Osofisan, A. O., (2012). Cloud Computing and Sustainable Development in Higher Education. Journal of Emerging Trends in Computing and Information Sciences, 3(11), 1466-1471.

Kalpeyeva, Z. B. \& Mustafina, A. K., (2013). IT-infrastructure of university based on cloud computing. IJCSI International Journal of Computer Science Issues, 10(5), 176-179.

Karajeh, H., Maqableh, M. \& Masa'deh, R. (2016). Privacy and Security Issues of Cloud Computing Environment. In Proceedings of the 23rd IBIMA Conference Vision 2020 (pp. 1-15).

Karim, F. \& Goodwin, R., (2013). Using Cloud Computing in E-learning Systems. International Journal of Advanced Research Computer Science \& Technology (IJARCST), 1(1), 65-69.

Khurana, S., \& Verma, A. G., (2013). Comparison of cloud computing service Models: SaaS, PaaS, IaaS, InternatIonal Journal of electronIcs \& communIcatIon technology, 4(3), 12-27.

Kovacevic, A. P., Spoljaric, M., \& Heði, I. (2012, June). Cloud-based Collaboration in Higher Education. In An Enterprise Odyssey. International Conference Proceedings (pp. 368-389). University of Zagreb, Faculty of 
Economics and Business.

Kumar, S. \& Murthy, O., (2013). Cloud Computing for Universities: A Prototype Suggestion and use of Cloud Computing in Academic Institutions. International Journal of Computer Applications, 70(14), 1-6. https://doi.org/10.5120/12027-7633

Lakshminarayanan, R., Kumar, B. \& Raju, M., (2011). Cloud Computing Benefits for Educational Institutions. In Second Interenational Conference of the Omani Society for Educational Technology, Muscat, Oman.

Mas'adeh, R. (2016). Cloud Computing Perceived Importance in the Middle Eastern Firms: The Cases of Jordan, Saudi Arabia and United Arab Emirates from the Operational Level. Communications and Network, 8(03), 103-117. https://doi.org/10.4236/cn.2016.83011

Masa'deh, R. E., Shannak, R., Maqableh, M., \& Tarhini, A. (2017). The Impact of Knowledge Management on Job Performance in Higher Education: The Case of the University of Jordan. Journal of Enterprise Information Management, 30(2), 244-262.

Mathew, S., (2012). Implementation of Cloud Computing in Education - A Revolution. International Journal of Computer Theory and Engineering, 4 (3), 473-475. https://doi.org/10.7763/IJCTE.2012.V4.511

Maqableh, M., Karajeh, H., \& Masa'deh, R. E. (2014). Job Scheduling for Cloud Computing Using Neural Networks. Communications and Network, 6(03), 191-200. https://doi.org/10.4236/cn.2014.63021

Mell, P. \& Grance, T. (2011). The NIST Definition of Cloud Computing. National Institute of Standards and Technology (pp. 1-3.). https://doi.org/10.6028/nist.sp.800-145

Mircea, M. \& Andreescu, A. I., (2011). Using Cloud Computing in Higher Education: A Strategy to Improve Agility in the Current Financial Crisis. Communication of the IBIMA. 2011, 1-15. https://doi.org/10.5171/2011.875547

Morgado, E. M., (2011). An exploratory essay on Cloud Computing and its Impact on the use of Information and Communication Technologies in Education. Education in a technological world, 2(3), 68-71.

Mylavarapu, V. K., (2011). Taking testing to the cloud. Cognizant Reports.

Nair, S., (2012). Cloud Computing: An Emerging Technology in the Sultanate of Oman. International journal of advanced research in computer science and software engineering, 2 (10), 376-380.

Obeidat, B. Y., Al-Suradi, M., Masa'deh, R. \& Tarhini, A. (2016). The impact of knowledge management on innovation: An empirical study on Jordanian consultancy firms. Management Research Review, 39(10), 1214-1238. https://doi.org/10.1108/MRR-09-2015-0214

Orozco, J., Tarhini, A., \& Tarhini, T. (2015). A framework of IS/business alignment management practices to improve the design of IT Governance architectures. International Journal of Business and Management, 10(4), 1-12. https://doi.org/10.5539/ijbm.v10n4p1

Qasim, H., \& Abu-Shanab, E. (2014). Cloud computing risks \& business adoption. International Journal of Emerging Sciences, 4(2), 52-63.

Rao, C. C., Leelarani, M. \& Kumar, Y. R., (2013). Cloud: Computing Services and Deployment Models. International Journal of Engineering and Computer Science, 2 (13), 3389-3392.

Rao, K. S. \& Challa, R. K., (2013). Adoption of cloud computing in education and learning. International Journal of Advanced Research in Computer and Communication Engineering, 2(10), 4160-4163.

Rogers, O. \& Cliff, D., (2012). A financial brokerage model for cloud computing. Journal of Cloud Computing, 1 (1), 1-12. https://doi.org/10.1186/2192-113x-1-2

Saleh, S. K. \& Abdalla, A. G. E., (2014). The Role and Benefits of Implementing Cloud Computing System in Sudanese Higher Education Institutions. International Journal of Computer Engineering and Applications, 7 (3), 81-87.

Sharma, S. K., Govindaluri, S. M., Muharrami, S. M., \& Tarhini, A. (2017). A multi-analytical model for mobile banking adoption: A developing country perspective. Review of International Business and Strategy, 27(1), $1-27$.

Sharma, S. K., Al-Badi, A. H., Govindaluri, S. M., \& Al-Kharusi, M. H. (2016). Predicting motivators of cloud computing adoption: A developing country perspective. Computers in Human Behavior, 62, 61-69. https://doi.org/10.1016/j.chb.2016.03.073 
Shunye, W., Dayong, L. \& Zijuan, Z., (2014). E-Learning system architecture based on Private Cloud for university. Journal of Chemical and Pharmaceutical Research, 6 (5), 492-498.

Sinjilawi, Y. K., Al-Nabhan, M. Q., \& Abu-Shanab, E. A. (2014). Addressing security and privacy issues in cloud computing. Journal of Emerging Technologies in Web Intelligence, 6(2), 192-199. https://doi.org/10.4304/jetwi.6.2.192-199

Singh, A. \& Hemalatha, M., (2012). Cloud Computing for Academic Environment. International Journal of Information and Communication Technology Research, 2 (2), 97-101.

Srinivasan, S. (2014). Cloud Computing Basics. Springer, NY:USA. https://doi.org/10.1007/978-1-4614-7699-3

Sultan, N. (2010). Cloud computing for education: A new dawn?. International Journal of Information Management, 30 (2), 109-116. https://doi.org/10.1016/j.ijinfomgt.2009.09.004

Tarhini, A., Hone, K., \& Liu, X. (2014). The effects of individual differences on e-learning users' behaviour in developing countries: A structural equation model. Computers in Human Behavior, 41, 153-163. https://doi.org/10.1016/j.chb.2014.09.020

Tarhini, A., Hone, K., \& Liu, X. (2015). A cross - cultural examination of the impact of social, organisational and individual factors on educational technology acceptance between British and Lebanese university students. British Journal of Educational Technology, 46(4), 739-755. https://doi.org/10.1111/bjet.12169

Tarhini, A., Teo, T., \& Tarhini, T. (2016). A cross-cultural validity of the E-learning Acceptance Measure (ElAM) in Lebanon and England: A confirmatory factor analysis. Education and Information Technologies, 21(5), 1269-1282. https://doi.org/10.1007/s10639-015-9381-9

Tarhini, A., El-Masri, M., Ali, M., \& Serrano, A. (2016). Extending the UTAUT model to understand the customers' acceptance and use of internet banking in Lebanon: A structural equation modeling approach. Information Technology \& People, 29(4), 830-849. https://doi.org/10.1108/ITP-02-2014-0034

Viswanath, D. K., S.Kusuma \& Gupta, S. K., (2012). Cloud Computing Issues and Benefits Modern Education. Double Blind Peer Reviewed International Research Journal, 12 (10), 14-20.

Vitkar, S., (2012). Cloud Based Model for E-Learning in Higher Education. International Journal of Advanced Engineering Technology, 3 (4), 38-42.

Wood, T., Cecchet, E., Ramakrishnan, K., Shenoy, P., Van Der Merwe, J. \& Venkataramani, A., (2010). Disaster recovery as a cloud service: Economic benefits \& deployment challenges. In the proceeding of 2nd USENIX Workshop on Hot Topics in Cloud Computing, Berlin, Germany (pp. 1-7).

Yadav, K., (2014). Role of Cloud Computing in Education. International Journal of Innovative Research in Computer and Communication Engineering, 2 (2), 3108-3112.

Yadav, N., Khatri, S. \& Singh, V. (2014). Developing an intelligent cloud for higher education. ACM SIGSOFT Software Engineering Notes, 39 (1), 1-5. https://doi.org/10.1145/2557833.2557854

\section{Copyrights}

Copyright for this article is retained by the author(s), with first publication rights granted to the journal.

This is an open-access article distributed under the terms and conditions of the Creative Commons Attribution license (http://creativecommons.org/licenses/by/4.0/). 